\title{
Pemodelan Keputusan Membuat dan atau Membeli Bahan Baku pada Sistem Produksi Asam Fosfat untuk Mengoptimalkan Pendapatan di PT Petro Jordan Abadi
}

\author{
Aldhiaz Pradipta Ichromantoro, Yudha Andrian Saputra \\ Departemen Teknik Industri, Fakultas Teknologi Industri, Institut Teknologi Sepuluh Nopember (ITS) \\ e-mail: yudha.andrian@gmail.com
}

\begin{abstract}
Abstrak-Tingginya biaya produksi asam fosfat atau cost of goods sold disebabkan oleh keputusan penentuan proporsi dalam membuat dan atau membeli bahan baku asam fosfat. Perusahaan memiliki plant yang saling mendukung, dimana plant utama membutuhkan bahan baku yang dapat diproduksi oleh plant lainnya. Laporan perusahaan pada tahun 2015 hingga 2016 menunjukkan bahwa beberapa plant pendukung tersebut tidak aktif sepenuhnya, sehingga hampir seluruh bahan baku membeli dari perusahaan lain. Dengan mempertimbangkan aspek depresiasi, perusahaan mengalami kerugian pada earning before interest and tax atau EBIT. Namun terdapat beberapa periode yang dengan proporsi production rate tertentu, perusahaan berhasil menekan COGS sehingga harga pokok produksi lebih rendah dari keuntungan penjualan. Sehingga EBIT perusahaan menguntungkan. Oleh karena itu perlu dilakukan perhitungan untuk menentukan batasan proporsi production rate yang menguntungkan tersebut. Hasil dari penelitian ini menunjukkan batas atas dan batas bawah production rate untuk tiap plant dengan menggunakan analisis sensitivitas dan fungsi what-if analysis.
\end{abstract}

Kata Kunci-Asam Fosfat, Analisis Sensitivitas, Analisis Keputusan, EBIT.

\section{PENDAHULUAN}

$\mathrm{B}$ ERDASAR laporan keuangan PT Petrokimia Gresik pada tahun 2013, jumlah impor bahan baku asam fosfat sangat fluktuatif dan memiliki trend line positif. Hal tersebut diakibatkan oleh kebutuhan bahan baku dalam memproduksi pupuk majemuk yang juga meningkat setiap tahunnya. Rata rata setiap tahun mengimpor sebanyak 74,500 Ton asam fosfat dengan nilai tertinggi impor sebesar 272,548 Ton pada tahun 2011 [1]. Oleh karena itu pembangunan pabrik penghasil asam fosfat menjadi salah satu faktor penting dalam menstabilkan ketersediaan bahan baku dan menekan biaya pokok produksi.

PT Petro Jordan Abadi memiliki tiga fasilitas utama dan dua fasilitas pendukung agar dapat meminimalkan biaya produksi dan meningkatkan pendapatan. Tiga fasilitas utama tersebut adalah Sulfuric Acid Plant, Phosphoric Acid Plant, dan Granulated Gypsum Plant. Sedangkan dua fasilitas pendukungnya adalah Steam Turbine Generator dan Coal Boiler Plant. Pada dasarnya, asam fosfat diproduksi hanya dengan menggunakan proses hemihydrate dengan bahan baku utama batuan fosfat, asam sulfat, dan uap. Uap dan asam sulfat dipasok oleh fasilitas pabrik pertama yakni Sulfuric Acid Plant. Hasil pengolahan dari Phosphoric Acid Plant berupa asam fosfat yang mana memliki produk sampingan Fluosilicic Acid plant dan Phosphoric Gypsum. Fluosilicic Acid bisa langsung dijual, sedangkan Phosphoric Gypsum menjadi bahan untuk fasilitas ketiga yaitu Granulated Gypsum Plant. Sehingga terdapat total 3 produk utama yang dapat dijual ke pasar, antara lain asam fosfat $\left(\mathrm{H}_{3} \mathrm{PO}_{4}\right)$, Granulated Gypsum $\left(\mathrm{CaSO}_{4}, 2 \mathrm{H}_{2} \mathrm{O}\right)$, dan Fluosilicicic Acid $\left(\mathrm{H}_{2} \mathrm{SiF}_{6}\right)$. Disamping itu juga, produksi uap yang berlebih dapat dimanfaatkan kembali menjadi tenaga untuk memasok kebutuhan listrik perusahaan.

Kondisi eksisting terhitung hingga akhir tahun 2016 ialah tidak diaktifkannya beberapa fasilitas seperti Sulphuric Acid Plant, Steam Turbine Generator, dan Coal Boiler plant. Alasan dimatikannya fasilitas asam sulfat adalah karena mahalnya bahan baku belerang (sulfur), batubara, dan biaya operasional. Karena plant tersebut tidak aktif, maka kebutuhan asam sulfat harus beli dari PT Petrokimia Gresik. Tidak hanya asam sulfat, kebutuhan uap juga sepenuhnya dipasok oleh PT Petrokimia Gresik. Matinya fasilitas asam sulfat berdampak pada non aktifnya Steam Turbine Generator, karena tidak ada lagi proses penurunan tekanan uap yang dibutuhkan. Sedangkan Coal Boiler Plant yang tidak aktif disebabkan oleh tingginya biaya kontrak dengan pihak ketiga sebagai pelaksana jalannya fasilitas dan harga batubara yang fluktuatif. Hal tersebut menyebabkan desain integrasi yang seharusnya menekan harga pokok produksi, berbalik menjadi beban biaya lebih bagi perusahaan.

Dari dua belas bulan periode produksi tahun 2016, sebelas bulan perusahaan mengalami kerugian. Keuntungan hanya diraih pada bulan Februari sebesar USD 532,985. Hal tersebut disebabkan oleh tingginya nilai penjualan asam fosfat. Namun pada bulan September dan November perusahaan merugi sebesar USD $(3,422,113)$ dan USD $(3,256,122)$. Padahal pendapatan hasil penjualan asam fosfat yang didapat kurang lebih sama dengan bulan Mei hingga Agustus. Bahkan nilai penjualan pada bulan Januari yang jauh lebih rendah dari bulan September, memiliki operating income yang lebih baik. 
Hal tersebut terjadi karena tingginya harga pokok produksi asam fosfat pada rentang Bulan Juni hingga bulan November. Tingginya harga pokok produksi disebabkan oleh keputusan pembuatan dan pembelian bahan baku yang kurang tepat pada paruh kedua.

Tinggi rendahnya harga pokok produksi akan berimbas pada pendapatan perusahaan. Pendapatan yang dimaksud ialah Earning before Interest and Tax atau bisa disebut dengan EBIT. Keputusan proporsi pembelian dan produksi yang buruk seperti pada bulan juni hingga November tahun 2016 menyebabkan neraca keuangan perusahaan merugi. Oleh karena itu perlu dimodelkan keputusan pembuatan dan atau pembelian bahan baku untuk mengoptimalkan EBIT perusahaan PT Petro Jordan Abadi.

\section{URAIAN PENELITIAN}

\section{A. Sulphuric Acid Plant}

Fasilitas tersebut memiliki kapasitas produksi maksimal 1850 Ton/Hari. teknologi yang digunakan oleh PT Petro Jordan Abadi adalah double contact/double absrobtion (DC/DA). Dalam setahun, fasilitas tersebut dapat berjalan selama 330 hari. Namun karena kapasitas produksi disesuaikan dengan kebutuhan dan biaya, maka produksi asam sulfat tidak pernah maksimal yang seharusnya bisa kurang lebih 600,000 ton/tahun. Selain itu fasilitas ini juga menghasilkan uap bertekanan tinggi $\left(36 \mathrm{~kg} / \mathrm{cm}^{2} \mathrm{~g}\right)$. Uap tersebut nantinya akan diturunkan tekanannya di fasilitas Steam Turbine Generator agar dapat kembali.

\section{B. Phosphoric Acid Plant}

PA Plant membutuhkan bahan baku primer atau utama berupa batuan fosfat (phosphate rock). Kapasitas produksi fasilitas ini sebesar 650 ton/hari, yang menggunakan teknologi proses HDH (Hemy-Hidrate). PA plant juga memilki produk sampingan berupa fluosilicic acid dan phospho gypsum. Namun apabila akan memproduksi phospho gypsum, akan dibutuhkan bahan baku tambahan berupa asam sulfat yang diproduksi oleh SA Plant. Akan tetapi apabila kapasitas produksi asam sulfat kurang mencukupi untuk proses produksi, dapat dilakukan impor asam sulfat dari PT Petrokimia Gresik.

\section{Granulated Gypsum Plant}

GG Plant merupakan fasilitas pendukung pada PT Petro Jordan Abadi yang memiliki tujuan utama memberi nilai tambah pada produk sampingan PA Plant. Produk utama dari GG Plant ialah granulated gypsum. Proses terbagi menjadi enam unit. Tidak banyak proses kimia yang terjadi pada sistem produksi GG Plant. Namun GG Plant juga membutuhkan uap bertekanan rendah dalam menjalankan produksi. Kapasitas produksi dari fasilitas ini sebesar 1800 ton/hari dengan teknologi purification-granulation.

\section{Steam Turbine Generator}

SSTG merupakan fasilitas PT Petro Jordan Abadi yang berfungsi sebegai pengolah uap bertekanan tinggi buangan dari SA Plant. Uap tekanan tinggi yang dihasilkan oleh SA Plant dapat dimanfaatkan kembali menjadi dua produk. Yang pertama dapat diolah menjadi uap bertekanan rendah, yang mana bisa digunakan oleh keseluruhan fasilitas. Atau diolah kembali menjadi listrik dengan kapasitas tertentu. , bahan baku utama dari proses produksi ialah high pressure steam dengan tekanan $36 \mathrm{~kg} / \mathrm{cm}^{2}$. Uap bertekanan tinggi tersebut akan diturunkan tekanannya menjadi $10 \mathrm{~kg} / \mathrm{cm}^{2}$ agar dapat dimanfaatkan kembali oleh fasilitas lain. Namun alternatif lain dari pengolahan untuk menjadi uap ialah diolah untuk menjadi listrik. Apabila diolah menjadi listrik, akan menghasilkan listrik sebesar 17.5 MW.

\section{E. Coal Boiler Plant}

Boiler merupakan suatu bejana tertutup yang digunakan untuk menghasilkan uap (steam). Uap yang dihasilkan pada suhu dan tekanan tertentu tersebut kemudian digunakan untuk mentransferkan energi ke suatu proses. Uap merupakan salah satu media mengalirkan panas ke suatu proses dengan murah dan efektif. Dengan melakukan pendidihan air hingga menjadi uap maka volume akan meningkat hingga 1600 kali.

Coal Boiler memiliki fokusan untuk memproduksi uap bertekanan rendah bagi semua fasilitas pabrik. Bahan utama dari fasilitas ini ialah batubara yang diproses melalui proses pembakaran untuk menghasilkan uap. Namun pada kenyataannya, kapasitas produksi coal boiler tidak pernah dimaksimalkan karena naik turunnya harga batubara. Selain itu juga steam atau uap bertekanan rendah juga dapat diimpor melalui PT Petrokimia Gresik. Sehingga, perlu dilakukan kombinasi produksi uap bertekanan rendah antara SA Plant, Coal Boiler Plant, dan impor dari PT Petrokimia Gresik.

\section{F. PT Petro Jordan Abadi}

Produk utama dari PT Petro Jordan Abadi adalah asam fosfat (phosphoric acid) dengan produk sampingan granulated gypsum, dan fluosilicic acid. Namun di dalam fasilitas pabrik juga memiliki plant lain yang memproduksi asam sulfat (sulfuric acid), listrik, dan juga uap (steam). Produk asam fosfat dan fluosilicic acid difokuskan untuk memasok kebutuhan PT Petrokimia Gresik. Sedangkan produk granulated gypsum yang merupakan bahan baku pembuatan semen selama ini dijual ke PT Semen Gresik.

Dalam komplek pabrik, perusahaan memiliki tiga plant utama dengan dua plant pendukung. Plant tersebut adalah sulphuric acid plant, phosphoric acid plant, dan granulated gypsum plant. Plant pendukung ketiga plant tersebut adalah steam turbine generator dan coal boiler plant. SA Plant menghasilkan produk asam sulfat, PA plant menghasilkan produk utama asam fosfat dan produk sampingan fluosikat (fluosilicic acid) dan phospho gypsum. Plant GG mengolah phospho gypsum untuk menjadi produk jual granulated gypsum. STG mengolah uap atau steam yang dihasilkan oleh SA plant agar dapat digunakan oleh plant lainnya dan untuk menjadi listrik. Sedangkan coal boiler plant fokus mengubah batubara menjadi uap yang dibutuhkan oleh keseluruhan plant. Hal tersebut karena uap yang dhasilkan oleh proses produksi di SA plant masih belum mencukupi untuk kebutuhan produksi 
keseluruhan plant.

\section{G. Earning Before Interest and Tax}

EBIT merupakan hasil perhitungan dari pendapatan penjualan (rеvenue) yang dikurangi dengan biaya penjualan/pengeluaran termasuk pembelian atau produksi bahan baku (expenditure) dan Fix Cost operasional perusahaan.

Menurut Accounting Principle Board Statement No. 4 pendapatan adalah peningkatan kotor aktiva atau penurunan kotor hutang yang diakui dan diukur sesuai dengan prinsip akuntansi umum yang berasal dari aktivitas perusahaan berorientasi laba yang mempengaruhi ekuitas pemilik [2]. Aktivitas perusahaan yang dimaksud tersebut adalah penjualan hasil produksi, penggunaan aktiva perusahan atau pembelian jasa dari pihak lain sehingga menghasilkan bunga sewa, honorium dan lainnya, serta penjualan sumber ekonomi selain hasil produksi seperti investasi di luar perusahaan.

Pengeluaran merupakan pembayaran yang dilakukan pada saat ini untuk kewajiban yang akan datang yang guna memperoleh keuntungan [3]. Pengeluaran dapat dikelompokkan menjadi dua yaitu [4]. Pengeluaran modal (capital expenditure) yaitu biaya-biaya yang dikeluarakan untuk memperoleh aset tetap, peningkatan efisiensi operasional, dan kapasitas produktif aset tetap, serta memperpanjang masa manfaat aset tetap. Pengeluaran pendapatan (revenue expenditure) merupakan biaya-biaya yang hanya akan memberikan manfaat dalam sebuah periode berjalan sehingga biaya-biaya yang dikeluarkan tidak dijadikan aset tetap di neraca namun langsung dibebankan pada laporan laba rugi.

\section{H. Decision Amalysis}

Decision Analysys atau analisa keputusan adalah teknik pendekatan untuk mengambil sebuah keputusan dengan mempertimbangkan segala kemungkinan terbaik dan terburuk dari hasil keputusan yang diambil. [5]. Dalam mengambil sebuah keputusan, perlu dijabarkan terlebih dahulu tujuan dari keputusan yang diambil dan alternatif yang tersedia. Tujuan dari pengambilan keputusan bisa jadi untuk maksimasi pendapatan, minimasi biaya, minimasi resiko, dan lain sebagainya. Hal ini bertujuan untuk mengerucutkan prioritas perusahaan dalam mengambil keputusan. Selain itu juga membantu perusahaan dalam menentukan apakah keputusan tersebut relevan dengan tujuan dari perusahaan. Penentuan tujuan berlanjut pada mengidentifikasi alternatif. Alternatif yang tersedia harus disistematiskan dengan berbagai konsekuensi yang sesuai terhadap tujuan yang dihadapi.

\section{Influence Diagram}

Influence diagram merupakan alat bantu dalam menampilkan permasalahan yang direpresentasikan menggunakan gambar [5]. Elemen yang berbeda direpresentasikan menggunakan geometri yang berbeda juga. Keterkaitan antar elemen keputusan dihubungkan menggunakan panah.

\section{J. Sensitivity Analysis}

Sensitivity analysis merupakan sebuah cara untuk mengevaluasi bagaimana sebuah input yang tidak pasti mempengaruhi output dari model [6]. Sensitivity analysis atau yang dikenal juga dengan what-if atau analisa simulasi merupakan langkah yang dilakukan untuk memperkirakan hasil dari sebuah keputusan dengan range variabel tertentu. Dalam one way sensitivity analysis hanya sebuah variabel yang diperhatikan untuk melihat kepentingan dari variabel tersebut terhadap indikator yang telah ditentukan.

Untuk melakukan one way sensitivity langkah yang dilakukan adalah dengan merubah naik-turun sebuah variabel kritis dalam range tertentu. Saat melakukan pengujian nilai dari variabel lainnya ditetapkan pada base value atau nilai yang mendekati nilai aktual.

\section{HASIL DAN DISKUSI}

\section{A. Sensitivity Analysis Production Rate Plant}

Dalam melakukan uji sensitivitas, hal pertama yang harus dilakukan adalah menentukan base value. Lalu yang kedua adalah menentukan batas atas dan bawah. Karena production rate plant berada pada rentang $0 \%$ hingga $100 \%$, maka angka tersebut yang digunakan. Lalu menentukan interval antar pengujian, yakni 4\%. Langkah terakhir ialah dengan menggunakan fungsi what-if dan subfungsi data table pada Microsoft excel, pengalian antara kapasitas produksi dengan production rate dilakukan secara otomatis. Selain itu korelasi formula dan model juga saling berkaitan, sehingga yang harus dilakukan hanya menentukan output yang dimaksud. Untuk kasus ini outputnya adalah Earnings Before Interest and Tax.

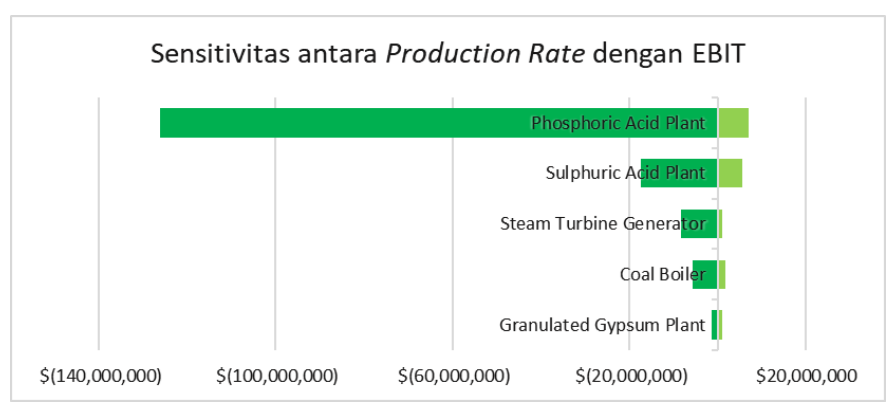

Gambar 1. Tornado Diagram Production Rate dengan EBIT

Melalui Gambar 1, dapat diketahui plant pendukung yang memiliki pengaruh terbesar kedua terhadap EBIT perusahaan ialah sulphuric acid plant. Dengan selisih EBIT antara rentang atas dan bawah sebesar USD 22,939,200. Hal tersebut terjadi karena salah satu komponen utama asam fosfat adalah asam sulfat. Sedangkan $100 \%$ kebutuhan asam sulfat perusahaan dipasok oleh plant ini. Selain itu, produk sampingan dari sulphuric acid plant, menjadi bahan baku utama dalam menjalankan steam turbine generator. Steam turbine generator menjadi pemasok listrik utama dalam perusahaan. Berarti sulphuric acid plant secara langsung menjadi pemasok utama asam sulfat bagi perusahaan dan secara tidak langsung menjadi pemasok utama listrik di perusahaan. 


\section{B. Sensitivity Analysis Harga Bahan Baku}

Langkah dalam melakukan uji senstivitas sama dengan sensitivity analysis pada production rate plant. Namun yang beda pada sensitiviyy analysis harga bahan baku ini ialah penentuan low, base, dan high value harga. Untuk beberapa bahan baku, batas bawah, tengah, dan atas berdasar data historis yang ada. Sedangkan variabel lain dikalikan dengan 0.75 untuk batas bawah dan 1.25 untuk batas atas. Hasil running dari fungsi what-if data table di Microsoft Excel dapat dilihat pada lampiran. Tornado diagram hasil dari penjalanan fungsi tersebut dapat dilihat pada Gambar 2

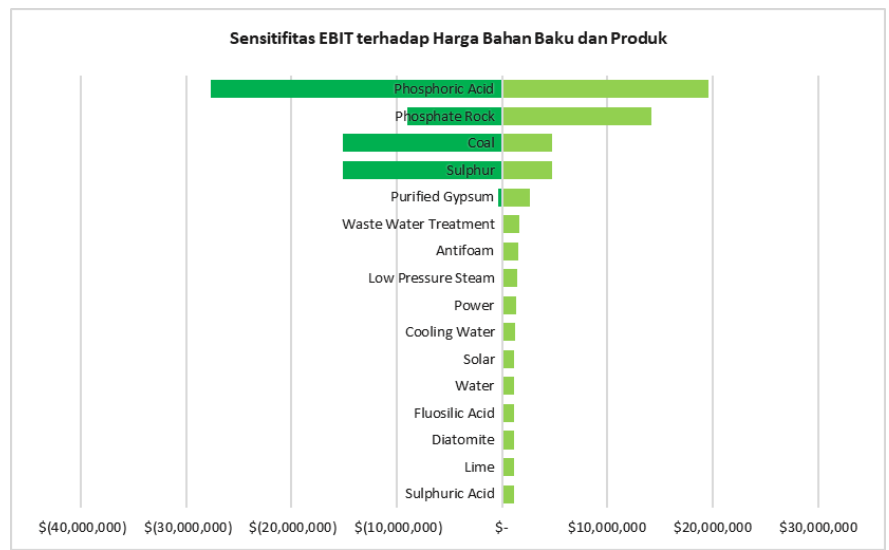

Gambar 2. Tornado Diagram Harga Bahan Baku terhadap EBIT

Coal atau batubara menjadi bahan baku tersensitif kedua karena produk dari coal boiler plant adalah low pressure steam. Sedangkan low pressure steam dibutuhkan oleh seluruh plant, kecuali steam turbine generator. Sehingga harga batubara mempengaruhi secara tidak langsung terhadap biaya produksi perusahaan. Berbeda tipis dengan batubara, sulphur atau belerang menjadi bahan baku tersensitif keempat. Alasan dari kesensitifan tersebut adalah sulfur menjadi bahan baku utama dalam sulfuric acid plant. Sedangkan sulphuric acid plant menjadi plant paling sensitif kedua setelah phosphoric acid plant, seperti yang dijelaskan dalam paragraph sebelumnya.

\section{Two-way Sensitivity Analysis}

Analisis senstivitas menggunakan fungsi what-if dengan subfungsi data table pada Microsoft Excel. Untuk kolom diisi oleh production rate coal boiler plant dan baris diisi production rate sulphuric acid plant. Hasil dari running dapat dilihat pada lampiran. Interval production rate 5\% dengan batas atas $100 \%$ dan bawah 0\%. Hasil running perhitungan dapat dilihat pada lampiran. Data tersebut akan dibuat grafik sensitivitasnya seperti pada Gambar 3 berikut. Terbaik terletak pada sulphuric acid plant 55\% - 80\% dengan coal boiler 75\%$100 \%$.

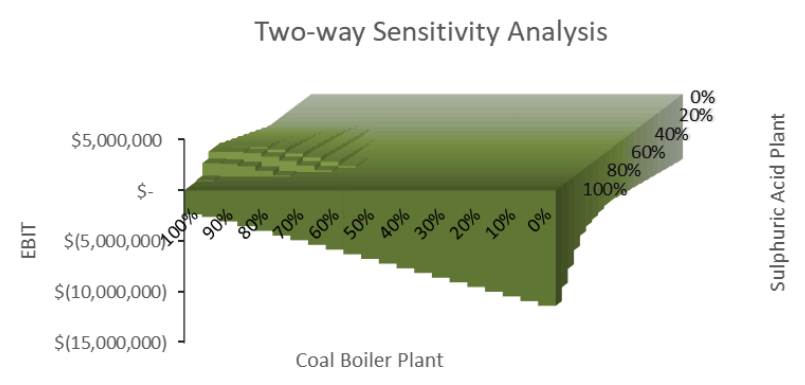

Gambar 3. Two-way Sensitivity Analysis Graph antara Production Rate Coal Boiler Plant dengan Sulphuric Acid Plant terhadap EBIT

EBIT dengan nilai yang paling merugikan terletak pada production rate sulphuric acid plant $100 \%$ dan coal boiler plant $0 \%$. Hal tersebut terjadi karena salah satu bahan baku pada sulphuric acid plant adalah low pressure steam. Sedangkan ketika coal boiler mati, low pressure steam seluruhnya harus diimpor. Yang notabene harganya enam kali lipat lebih mahal dari low pressure steam produksi dari coal boiler. Sehingga EBIT perusahaan menjadi sangat negatif dengan nilai USD - $(11,354,396)$ atau jika dirupiahkan hampir IDR 150 Milyar per tahun.

\section{Analisis Model Finansial}

Pada model finansial dapat diidentifkasi seberapa banyak penghematan yang dilakukan ketika melakukan produksi sendiri. Pada penentuan production rate, ditunjukkan perbandingan ketika sulphuric acid plant mati namun phosphoric acid plant masih tetap produksi. Material yang diproduksi sendiri memiliki nilai pasar sebesar USD 34,688,628. Namun biaya untuk memproduksi bahan baku tersebut hanya sebesar USD 26,059,178. Perbedaan sebesar USD 8,629,450 merupakan penghematan yang dilakukan oleh PT Petro Jordan Abadi apabila menjalankan production rate sesuai dengan RKAP 2017.

Melalui model finansial juga dapat diketahui potensi penjualan plant pendukung perusahaan. Dapat dilihat ketika plant pendukung berjalan dengan maksimal. Apabila kelebihan produksi bahan baku difasilitasi penjualannya dengan baik, maka PT Petro Jordan Abadi dapat menambah pemasukan sebesar USD 14,604,624. Yang mana potensi pemasukan sampingan tersebut paling besar berasal dari steam turbine generator dalam menghasilkan listrik. Power yang dihasilkan bernilai sebesar USD 9,917,424 di pasaran. Begitu juga sulphuric acid berlebih yang dihasilkan memiliki nilai sebesar USD 4,460,400. Sehingga perlu dipertimbangkan kembali untuk mencari pasar yang membutuhkan bahan baku low pressure steam, sulphuric acid, dan yang terpenting adalah power.

\section{E. Analisis Keputusan Membuat dan atau Membeli}

Dengan mempertimbangkan hal melalui proses perhitungan production rate sulphuric acid plant, steam turbine generator, dan coal boiler plant, ditemukan kebutuhan produksi tiga bahan baku utama yakni asam sulfat, listrik, dan low pressure 
steam. Pengujian skenario juga dilakukan untuk mengetahui bagaimana nilai EBIT ketika perusahaan mengambil alternatif untuk membeli bahan baku sepenuhnya, dipasok sendiri sepenuhnya untuk tiga bahan baku tersebut, dan produksi maksimal untuk ketiga plant melebih kebutuhan perusahaan. keuntungan terbesar terletak pada skenario dua yakni kebutuhan perusahaan dipasok sepenuhnya oleh ketiga plant yakni dengan nilai USD 2,276,899.

Dalam keputusan produksi asam sulfat, perusahaan masih meraup keuntungan yang tinggi ketika produksi asam sulfat hanya $50 \%$ dari kapasitas maksimal. Sehingga ketika perusahaan membutuhkan asam sulfat sejumlah 269,000 MT, memroduksi hanya 162,000 MT dan 107,000 MT sisanya membeli, perusahaan masih mendapat keuntungan sebesar USD 794,562. Batas kerugian sulphuric acid plant ketika produktifitas perusahaan kurang dari 20\% kapasitas maksimal. Hal tersebut tentu menjadi pertimbangan agar PT Petro Jordan Abadi selalu menjaga jalannya pabrik di atas $20 \%$ atau sekitar di atas 64,800 MT per semester. Dengan asumsi steam turbine generator jalan stabil dengan production rate $54 \%$. Perusahaan akan merugi jika memproduksi lebih dari 360,000 MT per semesternya (production rate $>90 \%$ ).

Sedangkan untuk produksi low pressure steam, perusahaan akan tetap meraup keuntungan apabila produktifitas coal boiler plant masih di atas $75 \%$. Sehingga apabila pada semester dua dibutuhkan low pressure steam seebesar 122,963,5 MT, coal boiler plant hanya memproduksi 105,750 MT dan membeli sebanyak 17,213,5 MT, perusahaan masih meraup keuntungan sebesar USD 807,165 dengan asumsi sulphuric acid plant dan steam turbine generator masih berjalan dengan batas normal. Namun apabila produktifitas coal boiler plant di bawah 55\% (77,550 MT) per semester, dipastikan perusahaan akan mengalami kerugian. Perusahaan juga akan merugi apabila memproduksi low pressure steam lebih dari 133,950 MT per semesternya (Production rate > $95 \%)$.

\section{KESIMPULAN/RINGKASAN}

1. Production rate dan produksi optimal untuk masing-masing plant pendukung dalam rangka memenuhi RKAP 2017 PT
Petro Jordan Abadi adalah untuk sulphuric acid 83\% (269,990 MT) pada semester 1 dan 78\% (252,010 MT) pada semester 2 sehingga rata-rata production rate dalam satu tahun $81 \%$ (522,000 MT). Untuk steam turbine generator sepanjang tahun 54\%. Dan yang terakhir coal boiler plant, pada paruh pertama sebesar 93\% (131,736.5 MT), $87 \%$ pada paruh kedua $(122,963.5 \mathrm{MT})$, dan rata-rata untuk setahun $90 \%(254,700$ MT). Sedangkan Area production rate terbaik terletak pada sulphuric acid plant $50 \%$ (162,000 MT) - 90\% (360,000 MT) dengan coal boiler 75\% (105,750 MT) - 95\% (133,950) agar EBIT masih dalam kategori menguntungkan.

2. Plant yang paling sensitif selain phosphoric acid plant terhadap EBIT adalah sulphuric acid plant dan steam turbine generator yang berperan besar dalam menekan biaya bahan baku sulphuric acid dan power. Sedangkan harga material yang paling sensitif terhadap EBIT selain phosphoric acid dan phosphate rock adalah coal atau batubara dan sulfur atau belerang. Dapat diketahui bahwa perusahaan memiliki potensi penjualan produk lain berupa low pressure steam sebesar USD 226,800, sulphuric acid sebesar USD 4,460,400, dan power sebesar USD 9,917,424. Selain itu juga perusahaan melakukan penghematan sebesar USD 8,629,450 apabila mengikuti production rate sesuai dengan kebutuhan.

\section{DAFTAR PUSTAKA}

[1] R. Agustina, "Perancangan Pabrik Asam Fosfat dengan Proses Nissan Kapasitas 100000 Ton/Tahun," Universitas Muhammadiyah Surakarta, 2014.

[2] S. M. Bragg, The Ultimate Accountants Reference. John Wiley \& Sons, 2003.

[3] A. Assegaf, Kamus Akuntansi. Jakarta: Mario Grafika, 2001.

[4] Hery, Accounting Principles. Jakarta: Grasindo, 2014.

[5] R. T. Clemen, Making Hard Decisions: an Introduction to Decision Analysis. Pacific Grove: Brooks/Cole Publishing Company, 2013.

[6] R. Gidwani, "Sensitivity Analyses for Decision Modeling." 2014. 